\title{
Research on modular analysis and evaluation method of ship repair cost
}

\author{
Zhong Qianghui ${ }^{1}$, Lin Mingchi ${ }^{1}$, Tang Yong $^{* 2}$ \\ ${ }^{1}$ Dept. of Management Engineering and Equipment Economics Naval Univ. of Engineering acceptable Wuhan, China \\ ${ }^{2}$ College of Mechanical and Electronic Engineering Wuhan Donghu University acceptable Wuhan, China
}

\begin{abstract}
Based on the idea of modular design of ship, the ship modular method is used to study the target cost of ship repair, and a modular decomposition and analysis method of ship repair cost is proposed to decompose the ship repair project into relatively independent sub-modules, standardizes the repair scope of sub modules, determines the repair cost standard of sub-modules, and accumulates the repair cost of corresponding sub-modules. At the same time, from the perspective of cost control, cost risks are identified, and the fuzzy analytic hierarchy process is applied to analyze and evaluate risk factors to lay the foundation for cost adjustment and cost reduction risks.
\end{abstract}

\section{Introduction}

In recent years, new types of naval vessels have been put into service in batches, and diversified military tasks such as large-scale actual combat exercises, cross-island chain voyages, Diaoyu Island Cruise, and Gulf of Aden escort have been increasing year by year. The task of ship maintenance and support has become increasingly heavy. Referring to the previous military price laws and regulations, the cost plus pricing mode of ship repair, which is calculated by adding up the repair contents one by one according to the repair engineering list of the whole ship, leads to the phenomenon of beyond the scope of repair work, the lack of cost control power of contractors, and the increasingly difficult pricing[1]. The new military bargaining rules promulgated in 2019 have made great innovations in the bargaining mode, mainly to move forward the price control work. Generally, the price work of equipment repair should be carried out in accordance with the procedures of repair target price demonstration, process cost control, bargaining cost confirmation, price negotiation, etc. After the repair target price demonstration is confirmed, the military and the contractor sign a temporary contract based on the target price. After the equipment repair project is completed for one year or the batch of equipment trial work is completed, the Contractor shall prepare an equipment repair price plan and provide complete, true and legal cost data, and the military shall organize cost audits to determine equipment repair bargaining costs.. If there are incentive and constraint bargaining clauses, the incentive and constraint profits shall be determined through negotiation based on the bargaining cost savings over the target cost; if there is no incentive and constraint clause, the target price is usually multiplied by the adjustment factor (such as 1.2) as the upper limit of the price, The price is negotiated and determined on the basis of bargaining cost and 5\% profit.

It can be seen that under the new bargaining rules, the repair target price of equipment is the core factor that runs through it. Because the repair target price is composed of the repair target cost and the target profit calculated by 5\% of the target cost, the interest focus of the military and contractors is actually the repair target cost, In order to solve the problem of determining the target price of ship equipment repair, improve the cost control of contractors, provide a reasonable basis and reference for the military to carry out cost audit, the modern management method of modular management is tried to introduce to create a ship repair cost analysis and evaluation method and obtain a more objective and reasonable repair target price plan. So far, the developed countries have widely adopted the modular design method in many projects, and achieved remarkable results. Typical cases include the US "sea wolf" attack nuclear submarine adopting the modular design idea, shortening the manufacturing cycle, speeding up the upgrading of the model, improving its reliability and maintainability, reducing the development cost; The Germany Navy has designed more than 40 warships for the navies of 8 countries by using modular design technology, which has been recognized as a practical and advanced design technology by the world shipbuilding industry[2-3]. In contrast, the domestic modular application is relatively backward, but it also presents a good application trend. At present, modular technology has been widely used in many civil and military industries, such as architecture, furniture, electronics, automobile, aircraft, ship. The modern shipbuilding industry is characterized by a wide range of social division of labor and specialized production. Ships need a large number of mechanical and electrical equipment, navigation instruments, communication facilities, automation devices

* Corresponding author: tangyong_tt@163.com 
and various accessories to be equipped. Therefore, under the guidance of the modular idea, more and more ship assembly plants are changing the old way of providing simple products or devices in the past, and changed to systematically supply the entire modules, freeing the shipyard from the "big and complete" bloated state, and concentrating on the ship assembly work.

This paper attempts to use the idea of modular design and production for reference to decompose the ship repair engineering into sub modules with relatively independent functions, standardize the repair scope of different repair levels of sub modules, determine the repair cost standard of sub -modules, and consider the risk factors to identify, analyze and evaluate the cost risk.

\section{The feasibility of modularization of ship repair}

Modular management is a modern management idea that emerged in the 1990s. Its basic principle is to divide the whole system into several modules from top to bottom layer by layer when dealing with complex problems. Each module completes a specific sub function, and all modules can be connected in a specific way to form a whole and complete the functions required by the whole system[4]. Modularization can simplify the complex structure and decompose the complex system into simple subsystems, making it easier to manage and implement.

Naval ship repair has its own characteristics. First, the task of ship repair is large, the time is relatively long, and the technical difficulty and complexity of repair engineering are large; second, ship repair needs to be divided into several projects for disassembly and repair, and each major project needs to be further divided into two or three levels, so as to be carried out in blocks; third, ship repair is usually carried out due to the small number of ships, even one model only has one ship, the ship repair is usually carried out as a single ship; fourthly, the ship repair procedure is relatively standard and strict, in the repair process, it is necessary to go through the standard process of $\mathrm{s}$ submit the engineering list, business department approval, engineering survey, construction plan and project details, and contract signing. The modular analysis of ship repair cost can sort out and decompose the complex problems and make it simpler. It can more scientifically and reasonably measure target prices and supply technical support for breaking down target costs and controlling repair costs. The feasibility mainly lies in the following aspects:

1) Modular management is widely used in modern shipbuilding. Although there are many types of naval ship equipment, the ship type and equipment system are in the same line, and the design of "generalization, serialization and combination" of equipment is constantly strengthened. In the process of shipbuilding, advanced regional and integrated manufacturing modern shipbuilding technology has also been applied. This technology focuses on intermediate products, divides the ship into several relatively independent functional areas or structural areas, implements the integrated and parallel construction of design, production and management, and integrates the concept of modular management. In the process of development and construction of warships, it lays a foundation for the application of modular management method to determine the cost of warship repair.

2) There is a clear distinction between ship repair engineering. At present, ship repair engineering is mainly divided into electromechanical engineering and special equipment engineering. Electromechanical engineering includes sub-engineering such as hull, turbine, electrical, piping, and docking, special equipment engineering includes sub-engineering such as armament, electronics, navigation All kinds of repair engineering are basically subject to independent management according to the specialty, with relatively clear interface and the conditions of splitting according to specific functional modules.

3) Contractor cost accounting and management are becoming more and more perfect. At present, most ship contractors are navy equipment support enterprises. After nearly 10 years of development, their cost accounting system is constantly improved, and their cost refined management ability is constantly improved. Most of them have established cost data analysis information management system, which creates favorable conditions for the collection and distribution of ship repair cost to modules.

4) Experience in the field of civil ships can be used for reference. The China Shipbuilding Industry Association has set a unified price for ship repair, and charges for the implementation of standards for mechanical equipment, electrical equipment, hull equipment and other modules for the repair of external and national ships. Modular management of ship repair cost plays an important role in regulating the reasonable competition and balanced development of civil ship repair market. Ship repair is basically similar to civil ship repair in ship repair process and technology. The successful experience of modular management method in the field of civil ship repair can provide important reference for its application in the field of ship repair price.

\section{Modular Decomposition And Analysis Of Ship Equipment Repair Costs}

In the ship structure, the ship type is different, but the structure type is similar, or the structure of different parts of the same ship is similar, which are the basis of the modularization of the ship structure. As a system, ship products have the following basic characteristics: Ship system is composed of several subsystems. Although the performance and function of each subsystem are different, they all follow the requirements of the overall function and coordinate with each other; The elements that constitute the ship system are organically connected and interrelated, and there is a specific relationship between them that interacts and restricts each other; The structure of ship products can be divided layer by layer according to the principle of functional decomposition until it is decomposed into the smallest parts.

Based on the above structural features, marine products can divide and combine modules of structures or systems according to the principle of functional 
decomposition. For example, the function modules of light frigate can be divided into living cabin module, weapon system module, shipboard platform module, automation system module, electromechanical device module, etc[5]. According to the principle of functional independence of module decomposition, considering the ship functional structure and repair technology, the ship repair engineering is divided into the following hierarchical modules:

The first-level module: considering that the determination of the ship repair level is based on the working time of the ship's electromechanical equipment, which is necessarily related to the repair level of special equipment. The ship system can be divided into electromechanical modules and special equipment modules.

The second-level module: considering the disciplines involved in ship construction, the electromechanical module is divided into sub-modules of dock engineering, hull engineering, power engineering, electrical engineering, piping engineering, and the special module is divided into sub-modules of armament engineering, electronic engineering, navigation engineering.

Three level module: considering the characteristics of two-level module, one type is subdivided by equipment model, such as power decomposition into main engine, auxiliary engine, gearbox, shafting, propeller, windlass, steering gear, pump, air compressor, fan, air conditioner, ice machine, water generator, sewage treatment device, kitchen equipment and other main model equipment; the other type is divided by material, such as the hull is decomposed into various types of steel plates, steel, ball flat steel.

The target cost calculation of ship repair based on the modular management method is to divide the ship repair project into sub-modules with relatively independent functions according to certain division criteria, standardize the repair scope of different repair levels of sub-modules, determine the repair cost standard of sub modules, and accumulate the repair cost of corresponding sub-modules. The cost analysis of ship repair based on modular management method mainly includes the following four links:

1) Repair engineering module decomposition. This work is the core of modular management, and also the key link of pricing model of ship repair price based on modular management method. For ship repair engineering, in the process of module decomposition, in addition to the basic principles of module decomposition, the actual situation of ship repair should also be considered, so that the decomposed sub-modules have appropriate levels, clear interfaces and independent functions.

2) Standardization of repair content. It is difficult to reasonably determine the repair price of a ship If the contents of the repair engineering list are arbitrarily compiled. Therefore, after the ship repair engineering module is decomposed, in order to facilitate the calculation of sub-module cost, the repair engineering list should be standardized. We can learn from the list pricing mode of the construction industry to implement standardization, that is, on the basis of the above module decomposition, for each type of ship, a list of sub-modules is established, referring to the historical experience of the naval contractors, the failure phenomenon of each submodule with different repair levels is analyzed, and then the standard repair content and corresponding standard repair process with different repair levels are determined.

3) Establish sub-module repair cost standard. On the basis of the standardization of the repair engineering list, according to the current data of the repair cost of the naval contractors, using mathematical statistics and other analysis methods, taking each sub module of different repair levels as the object, considering the corresponding profit rate, the corresponding repair price standard is set up. The price standard should be adjusted dynamically according to the adjustment of standard repair engineering list, the change of price index, the development of enterprise accounting system and the change of labor wage level, so as to ensure its scientific rationality.

4) The combination of modules forms the total cost. In the valuation of ship repair, the repair level of each sub module is determined first according to the engineering inspection, and then the total price is calculated according to the price standard of the corresponding repair level of the sub-module. In this process, if the repair content determined after the survey of a sub-module is between the two repair levels of the sub module, the repair price of the sub module is the low repair level price standard $\times(1$ + risk factor).

\section{Risk assessment of modular cost of ship equipment}

At present, the heavy responsibility of the ship and the high intensity of use have led to great uncertainty in ship repairs. Repairs beyond the scope of the project are not uncommon. Even if the ship repair works are decomposed to the module level, the uncertainty has been resolved to some extent, but the content of the scope of the project cannot be avoided. In order to better estimate the repair cost, it is necessary to analyze and evaluate the cost risk, and then provide the basis for correction.

\section{1 risk identification of ship repair}

Only by knowing the risk factors that threaten the repair cost in ship repair project, can we study them in depth. Therefore, it is first necessary to check each modularized project, identify what cost risk factors exist and what new cost risk factors may be generated, propose a cost risk list for ship repair modularization, and analyze the project cost risk incentives[6-7]. The possible cost loss is measured, and then measures are taken to avoid, eliminate or reduce the possible loss caused by risk factors.

1) Repair engineering list. It is an important factor to determine the repair cost of ship equipment that the repair engineering list directly indicates the scope of work and technical requirements of ship equipment repair. In short, the scope of ship equipment repair is large, and the repair cost is high. The list of ship equipment repair works plays an important role in guiding the inspection project. It is necessary to make clear which equipment should be repaired, to what extent, what technical requirements or 
applicable technical standards, and which involved projects, etc. Otherwise, it will affect the construction, and then affect the cost of ship equipment repair. Therefore, the determination of engineering list of ship equipment repair, that is, the determination of engineering scope and requirements, is an important aspect of controlling the repair price of ship equipment.

2) Repair survey. At the stage of survey and repair engineering projects, whether the project can be meticulous, accurate in scope, clearly implicated and less hidden is an important factor affecting the accuracy of cost estimation, which can also be called a key factor. A general description of the scope of repair work can not only cause troubles to the engineering appraisers of the enterprise, but also give give repairers an opportunity to take advantage of them. It also brings risks to the estimated cost. The price of a single repair project may be overestimated or underestimated. Therefore, the process and work of onsite inspection and repair works are very important. The factory appraisers, usually together with the production management personnel (supervision and repair personnel), should go to the site to find out the scope of repair and related implicated works, and reduce the hidden implicated works, so as to achieve the correct evaluation, accurate quotation and risk reduction.

3) Repair plan. The difference between repair plans will greatly affect the final repair cost. Due to the change of repair technology, the contractor must consider its own cost risks according to different construction methods and technical conditions, especially when choosing a more complex and difficult technical solution. the success probability of technology and the resulting cost risks should be fully considered.

4) Price adjustment of raw materials and equipment. The types and amounts of spare parts on board the ship during construction are restricted. Even if equipped, and the maintenance and repair process will encounter the problem of purchasing spare parts produced by these unique contractors. The resulting cost increase and price increase have to be borne by the order, thereby increasing maintenance costs. At the same time, the prices of other raw materials and spare parts required for the repair of naval ship equipment will continue to change due to market adjustments.

5) Price change. Changes in domestic and international price fluctuations, not only the increase in the prices of raw materials and equipment and spare parts will affect the repair cost, but also the increase in travel expenses, water and electricity costs will also affect the repair cost. Repair costs are mainly composed of material costs, wages, manufacturing costs, special fees, management fees, and profits. Wage costs, manufacturing costs, and management costs can all be measured by different working hour rates. Obviously, changes in material prices and price levels will directly affect the cost of materials and working hours. There are many economic indexes used to reflect the degree of changes in the price level of economic activities, such as the common consumer price index (CPI) and industrial product price index (PPI).

6) Technical level of repair. The technical level of the enterprise includes the advanced level of maintenance equipment and test equipment., the completeness of technical documents, and the overall quality of the technical team and the reasonable conduct of the structure. The technologically advanced unit, with high repair quality, can easily save materials, reduce labor consumption, shorten the cycle, and facilitate management. However, manufacturers with weak technical foundations are difficult to guarantee the quality of repairs, low production efficiency, more labor-intensive to complete the same production tasks, low material utilization rate, long cycle, will also lead to increased manufacturing costs and management costs. In a word, enterprises with high technology level are not only easy to guarantee the maintenance quality, but also have a good impact on improving the utilization rate of materials, saving working hours and shortening the period, and also on improving the management level.

7) Enterprise management level. The management level of repair enterprises is mainly reflected in the following aspects: Management of material and equipment supply; Management of maintenance progress; Management of production process.

\subsection{Risk assessment model}

\section{1) Risk factor decomposition and index system establishment}

Questionnaire method and expert scoring method were used to score the risk factors of ship repair cost. Through investigation, relevant experts and experienced equipment risk management personnel are invited for suggestions. The seven risk factor indicators of repair engineering list, repair survey, repair plan, price adjustment of raw materials and equipment, price change, repair technology level, enterprise management level described in the previous section can be further decomposed, as shown in Table 1.

Table1. Risk factor index of ship repair cost

\begin{tabular}{|c|c|}
\hline $\begin{array}{ll}\text { First } & \text { level } \\
\text { indicators } & \\
\end{array}$ & Second level indicators \\
\hline \multirow{2}{*}{$\begin{array}{l}\text { Repair } \\
\text { engineering list }\end{array}$} & 1.1 clarification of repair work scope \\
\hline & $\begin{array}{l}1.2 \text { determination of repair } \\
\text { requirements }\end{array}$ \\
\hline \multirow{3}{*}{$\begin{array}{l}\text { Repair } \\
\text { inspection }\end{array}$} & 2.1 technical status of equipment \\
\hline & 2.2 clarification of involved projects \\
\hline & 2.3 estimation of hidden projects \\
\hline \multirow[b]{2}{*}{ Repair plan } & 3.1 plan complexity \\
\hline & $\begin{array}{l}3.2 \quad \text { construction } \\
\text { coordination }\end{array}$ \\
\hline \multirow{2}{*}{$\begin{array}{l}\text { Price adjustment of } \\
\text { raw materials and } \\
\text { equipment }\end{array}$} & 4.1 unity of source \\
\hline & 4.2 price control \\
\hline \multirow{2}{*}{ Price change } & 5.1 consumer price index \\
\hline & 5.2 industrial product price index \\
\hline \multirow{2}{*}{$\begin{array}{l}\text { Technical level of } \\
\text { repair }\end{array}$} & 6.1 technological advancement \\
\hline & 6.2 technological maturity \\
\hline \multirow{3}{*}{$\begin{array}{l}\text { Enterprise } \\
\text { management level }\end{array}$} & $\begin{array}{l}7.1 \text { material and equipment supply } \\
\text { management }\end{array}$ \\
\hline & 7.2 maintenance progress management \\
\hline & 7.3 self-made production management \\
\hline
\end{tabular}


2) Risk evaluation using fuzzy analytic hierarchy process

Due to the non-continuity of risk factors, the evaluation and determination of risk factors are prone to errors, which leads to decision-making errors. More and more researchers have chosen to eliminate errors by using fuzzy theory to ensure the accuracy of research results. Fuzzy processing technology is more and more widely used in the field of system evaluation, and more and more researchers have made a lot of achievements.

Analytic hierarchy process (AHP) considers subjective and objective factors in risk evaluation, and ranks the risks that cannot be quantified, so that decision makers can make decisions based on this. Its basic idea is to decompose the complex evaluation problems that are difficult to analyze, obtain various constituent factors, and form a hierarchical structure according to the membership relationship. Under the upper level criterion, the factors at the same level are compared with each other according to the importance of the criterion, and the weights are given to construct the judgment matrix. The relative weight and the comprehensive weight order are obtained by calculation. At present, this method has been used in infrastructure, environmental assessment, project selection and effect analysis.

Fuzzy analytic hierarchy process (FAHP) is a combination of the advantages of the above two methods, which simplifies the complexity of people's judgment of the relative importance of the target. It has the characteristics of the ambiguity of the judgment matrix and the simplicity of calculation. The priority relationship matrix to quantitatively describe decision-making has the advantages of convenient and quick transformation[8].The application of FAHP in the cost risk management evaluation model not only simplifies the operation, but also improves the credibility of the decision-making results. Firstly, the cost risk structure model of each module of ship repair is established. According to the seven risk factors and their sub indicators, two different risk levels are formed.

On this basis, the FAHP is used to evaluate the weight of the cost risk factors of each ship repair module, and then the fuzzy evaluation method, data envelopment analysis method, expert scoring method and other methods are used to determine the risk coefficient for the sub-modules[]. The risk coefficient solves the price risk caused by the repair beyond the scope of work at the sub-module level, so that when the sub-module repair price is combined to form the total price, the overall price risk will beunder control, the scientificity and rationality of the price will be greatly improved, and it will be more easily recognized by both military and local parties.

\section{Conclusion}

The research on modular analysis and evaluation method of ship equipment repair cost provides technical means and methods for the demonstration of ship equipment repair target price, realizes the transformation from "individual cost pricing" to "social average cost pricing", provides technical support for the establishment of effective incentive and restraint mechanism, promotes the contractor to innovate technology, control cost, improve efficiency, maximizes the benefits of limited repair funds. At the same time, the interface of the repair contents of each sub-module will be clearer, which can reduce the repeated price auditing of the same system or equipment and improve the work efficiency.

\section{References}

1. W. H. Sun, M. Z. Pan, K. J. Gao, "Research on warship repair price control," China Shiprepair, vol. 30, pp. 36-41. Feb. 2017.

2. T. T. Wang, The Research of Modular Design Method for Ship, Zhenjiang: Jiangsu University of Science and Technology, 2011, pp. 2-4.

3. X. S. Yu, "Design and construction of naval vessels based on modularization technology",Ship Engineering, vol. 30, No.4, pp. 85-87, 2008.

4. C. X. Zhou, Application Research of Ship Outfiting Modular Design Based on Modern Shipbuilding Mode, Shanghai: Shanghai Jiao Tong University, 2008, pp. 2-6

5. Y. J. Wang, The Study of Light Frigate's Modularization Design Method, Harbin: Harbin Engineering Universtiy, 2009, pp. 35-36.

6. L. L. Li, Research of Engineering Project Risk Management, Wuhan: Huazhong University of Science and Technology, 2007, pp.10-12.

7. X. L. The Construction Cost Risk Management Research Based on FAHP, Xi'an: Xi'an University of architecture and technology, 2015, pp. 11-13.

8. Fuzzy Comprehensive Evaluation Method Based on AHP in The Application of The Construction Cost Risk Management Research, Lanzhou: Lanzhou Jiaotong University, 2016, pp. 17-24. 